the whole-timer if we also bear in mind the additional $2 / 11$ ths factor to be paid for simply not seeing private patients. The present $18 \%$ differential between full and part time is for an extra work commitment if one takes into account the travel time factor allowed in the maximum part-time contract. It now seems that the Government are offering this extra money for no extra commitment, surely a most unusual example of distorted thinking. Whatever has become of the concept of equal pay for equal work done?

I would ask those who seem so keen to accept these proposals to consider how divisive they are when professional unity is so important. The proposals would certainly force large numbers of part-timers to go whole-time, albeit unwillingly, thus limiting the choice in the private sector in many geographical areas in Britain. If we fall, no doubt the general practitioners will be the next to be threatened by a salaried service. This would result in the medical profession being totally under State control, and we would therefore become civil servants with all that that could mean to our professional freedom.

One doubts if many young men and women would want to come into such a system and therefore $I$ feel that our present stand is not, as many seem to think, a matter simply of private beds, but it is the future of our profession and with it the future of the National Health Service itself. -I am, etc.,

IAN K. MATHIE

North Tees General Hospital, Stockton-on-Tees, Cleveland

SIR,-As one of that large and relatively silent minority of doctors employed in the National Health Service who make up $45 \%$ of consultant staff, I would like to put forward some of my views as a full-time consultant.

To me the greatest advantage is the clinical freedom to provide the best available service to the patient without having to consider the financial relationship between myself and my patient. My clinical freedom is unrestricted by considerations as to whether it is more profitable to me to operate on the patient or to treat him conservatively such as would be liable to arise in an itemof-service system. I also appreciate the freedom of not being remunerated on an hourly basis. I am not placed in the position that if I should take a little longer over an operation I would receive additional payment or if I delay seeing an emergency for half an hour I am eligible for an out-ofhours payment.

There is always a possibility that dedication to clinical work may be exploited and most of us would wish for protection from this. I will never forget the additional work load and perpetual on-call responsibility which fell upon me when a colleague was taken ill. At least if we were substantially remunerated for such additional work load employing authorities would have an incentive to provide relief. I should like a system of off-duty entitlement basically similar to that negotiated on behalf of junior hospital staff and I would only wish to be paid extra when an agreed normal work load was exceeded.
The $1 \%$ of hospital patients in private beds generate a great deal of emotion. It seems to me wrong that the treatment of such a small proportion of the population should bring such disproportionately high rewards to a minority of consultants and that so many others should try to emulate their more successful colleagues in private practice. If the N.H.S. is to attract the best of the profession to devote the whole of their energies to the Service the Department of Health must pay them to do this. I cannot see why a total commitment payment should in this context be emotively termed a bribe unless it is done for the purpose of furthering a particular political ideology.

Merit awards, to most of our minds, seem acceptable only if we have one and unmeritorious if we do not have one. Surely payment for merit should be attached to posts which demand merit to fulfil them. The profession would be in a position to compete for such senior posts in an open market. Such posts would be available in every district and the definition of seniority would cover the additional clinical, research, and administrative responsibilities of such posts.

I would ask for a substantial basic salary which does not have to be made up by additional payments to any great extent. Politicians and the public are not deceived by a remuneration which is made up of many different items, they all know about "overtime" and "bonus." A factor which must act to the detriment of the consultant starting at the bottom of the salary scale is the public image of the consultant earning up to $£ 16,000$ a year. With this image in front of the public how can we expect the support of the country in an improvement of the remuneration of the majority? There must be a reduction in the differential between the lowest and the highest paid members of the profession if the lowest are to get anything worthwhile.-I am, etc.

Rehabilitation Department, Pinderfields General Hospital,

J. F. PATrick Wakefield, Yorks

SIR,-The following motion was passed at the last meeting of the Executive Committee of the Lewisham Division of the British Medical Association.

"The Executive Committee of the Lewisham Division of the B.M.A. express their full support for any sanctions that the consultants may use in their struggle for a just contract."-I am, etc.,

London S.E.6

A. H. W. BaIN Hon. Secretary

SIR,-One of the causes of the long waiting lists for admission to N.H.S. hospitals in some areas has been the closure of wards owing to the lack of cleaning staff. Might I suggest that an urgent priority for our employers should be to prevent the diversion of our skilled manpower into private work outside the N.H.S.? To this end these admirable ladies and gentlemen should be asked to sign a contract of employment committing themselves to full-time N.H.S. work and undertaking not to work for any private employers in their spare time; and those who decline to sign such a contract should have their N.H.S. wages reduced.

This would solve the problems facing the N.H.S. at a stroke.-I am, etc.,

Andover, Hants

M. J. LockwOOD

\section{Common Approach}

SIR,-The junior doctors committee of this hospital feels that too much energy is wasted in rivalry between the Hospital Junior Staffs Group Council and the Junior Hospital Doctors Association when trying to overcome a common problem. Could these two bodies follow the consultants, who have persuaded the B.M.A. and the Hospital Consultants and Specialists Association to work together?

We also consider that in the present crisis the junior doctors and consultants would benefit from a common approach.-We are, etc.,

\section{A. R. GAYMER \\ (Chairman) \\ A. B. KASB \\ V. GRAHAM \\ N. A. OLBOURNE \\ J. MOLFE}

Salisbury General Hospital,

Salisbury

$$
\begin{aligned}
& \text { J. P. CAlvert } \\
& \text { R. T. JOHN } \\
& \text { J. A. CEMBala } \\
& \text { C. J. S. NYE } \\
& \text { M. TRAUB } \\
& \text { A. N. EMERY } \\
& \text { E. M. J. A. Fossion }
\end{aligned}
$$

\section{Sanctions}

SIR,-Like other consultants I may soon be asked to take industrial action in support of the profession's claim for more remuneration. It is my intention not to take such action for the following reasons.

(1) Working to contract (that is, $11 \times 3 \frac{1}{2}$ hours per week) will limit my freedom to work to a variable time-table according to patient needs and my own convenience. This freedom I consider a valuable and necessary privilege earned by "continuous responsibility." We already fear demands to "clock in," and working to contract will support those who wish to see us regimented.

(2) Working to contract may increase surgical waiting lists but only for benign conditions. I presume cancer will still be called urgent as it was during the ancillary workers' strike. How sensitive is the Government to large waiting lists for hernias or varicose veins, or even painful hips? If $I$, as a physician, see fewer outpatients there will be no epidemics of death or disability such as may follow interruption of water and sewage services. Remember how few people need consultant care but remember also that in certain cases our work is too important to be interrupted by strikes. Some patients do die or get near to death while awaiting consultant care which could prevent

it. Moreover, much of our work is directed to preventing illness-for example, by treating hypertension or diabetes. Our opponents will not be influenced by an increased incidence of vascular disease in 10 years' time.

(3) We already regret the decreasing continuity of patient care. This tendency will be aggravated if consultants adopt a clock-watching attitude or even appear to do so.

(4) The B.M.A. Secretary has written "It is sad that sanctions are bound to cause inconvenience to patients." This remark 